\title{
Bioproduction of Ethanol in Separate Hydrolysis and Fermentation and Simultaneous Saccharification and Fermentation from Cassava Stalks
}

\author{
Buddhiporn Sovorawet and Jirasak Kongkiattikajorn \\ School of Bioresources and Technology, King Mongkut's University of Technology Thonburi, Bangkok 10150, Thailand
}

Received: November 18, 2011 / Published: February 20, 2012.

\begin{abstract}
Cellulose biomass is being investigated as a potential substrate for bioethanol production. Cassava stalks were successfully converted to ethanol by fermentation using Saccharomyces cerevisiae TISTR5048, S. cerevisiae KM1195, S. cerevisiae KM7253 and co-culture of $S$. cerevisiae TISTR5048 and Candida tropicalis TISTR5045. The objective of this study was to assess the ethanol production from cassava stalks by dilute-acid pretreatment and enzymatic hydrolysis that were convertible into ethanol by mono-culture and co-culture of yeast strain. Cassava stalks $1.5 \%(\mathrm{w} / \mathrm{v})$ in $0.1 \mathrm{M}$ sulfuric acid was pretreated for $30 \mathrm{~min}$ at $135^{\circ} \mathrm{C}$ under the pressure of $15 \mathrm{lb} / \mathrm{inch}^{2}$. The pretreated cassava stalk suspensions were neutralized to $\mathrm{pH} 5.5$ for saccharification process. The enzyme solution ( $\alpha$-amylase, amyloglucosidase, cellulase, xylanase and pectinase solubilized in buffer $\mathrm{pH}$ 5.0) was used for hydrolysis of pretreated cassava stalk at $50{ }^{\circ} \mathrm{C}$ for $24 \mathrm{~h}$. The hydrolyaste was supplemented with additional nutrients. The culture was incubated at $30{ }^{\circ} \mathrm{C}$. The pretreatment of the stalk with dilute-acid resulted sugar yield of $0.57 \mathrm{~g} / \mathrm{g}$ dry matter from enzymatic hydrolysis, which was higher than dilute-alkaline-pretreated and distilled water-pretreated stalk. The sugar hydrolysate was bioconverted to ethanol with separate hydrolysis and fermentation (SHF) and simultaneous saccharification and fermentation (SSF). The highest ethanol yields of 98.43\% and $95.29 \%$ were obtained in SHF and SSF, respectively by S. cerevisiae KM1195. The fermentation time of SSF process was 24-32 $\mathrm{h}$ shorter than that of the SHF $\approx 56 \mathrm{~h})$, but not significantly leading to difference in ethanol production $(5.42 \mathrm{~g} / \mathrm{L}-6.22 \mathrm{~g} / \mathrm{L}$ for $\mathrm{SSF} ; 5.9 \mathrm{~g} / \mathrm{L}-6.23 \mathrm{~g} / \mathrm{L}$ for SHF).
\end{abstract}

Key words: Ethanol, cassava stalk, fermentation.

\section{Introduction}

Cassava (Manihot esculenta Cranz) is considered an important source of food and dietary calories for a large population in tropical countries in Asia, Africa and Latin America. Cassava ranks as the world's sixth most important food crop and is the basic food for more than 700 million people in several countries [1-2]. It has the remarkable capacity to adapt to various agro-ecological conditions. It is also considered as a low-risk crop. In view of its drought-resistant nature and non-requirement of any specific growth conditions,

Corresponding author: Jirasak Kongkiattikajorn, Ph.D., research fields: food chemistry and biochemistry, fermentation, bioactive compounds, enzyme technology. E-mail: jirasak.kon@kmutt.ac.th. much attention has been paid in the past 15-20 years to its agricultural aspects, for increasing its production all over the world, which has been well achieved. Cassava is a bushy plant producing tubers and is made up of an aerial part or stalk and an underground part. The stalk can be as high as 2-4 m with a trunk and branches on it. The underground part consists of two types of roots: the ones responsible for the plant nutrition, and the others with axial disposition surrounding the trunk. In recent years, there has been an increasing trend towards more efficient utilization of agro-industrial residues such as cassava bagasse, sugar cane bagasse, sugar beet pulp, coffee pulp/husk, apple pomace, etc. Several processes have been developed that utilize these as raw materials for the production of bulk chemicals and 
value-added fine products, such as ethanol, single cell protein (SCP), mushrooms, enzymes, organic acids, amino acids, biologically active secondary metabolites, etc. [3-5]. Application of agro-industrial residues in bioprocesses on the one hand provides alternative substrates, and on the other hand helps in solving pollution problems, which their disposal may otherwise cause. In addition, a reduction of the cost of the fine products, such as ethanol, can be achieved by reducing the cost of the raw materials. With the advent of biotechnological innovations, mainly in the area of enzyme and fermentation technology, many new avenues have opened for their utilization.

Bioethanol, a renewable fuel is becoming increasingly important as a consequence of major concern for depleting oil reserves, rising crude oil prices and greenhouse effect [6]. Agro-industrial residue feedstock is considered as an attractive raw material not only for the liquid transportation fuel but also for the production of chemicals and materials, i.e. the development of carbohydrate-based biorefineries [7] because of its availability in large quantities at low cost [8]. Over the past few years, ever since the energy crunch began, there has been a tremendous interest in energy saving both on new and existing structures. Using certain materials and techniques can result in big savings. Today, the idea of utilizing biomass from agricultural and livestock wastes as a raw material for production of ethanol has attracted the interest of researchers especially in agricultural practicing countries. Thailand has an abundance of agriculture by-products available which are usually directly discharged as solid waste; causing environmental issues.

Thailand is an agricultural country. Each year the country produced not only agricultural product but also more than 50 million tons of agricultural residues. Cassava stalk is the fourth largest agricultural residues which accounted more than 4 million tons per year [9]. Cassava stalk was considered as useless agricultural residues. To fully utilize the cassava stem as a feedstock for ethanol production, pretreatment is required to render the cellulose fibers more amenable to the action of the hydrolytic enzymes.

In order to obtain fermentable sugars from the biomass, the biomass needs to be hydrolyzed. In an enzymatic process this calls for a pretreatment step, during which the biomass is made more accessible to enzymatic hydrolysis. The obtained monosaccharides from the enzymatic hydrolysis step, can be fermented to ethanol using microorganism. The fermentation can be made either together with the enzymatic degradation, known as simultaneous saccharification and fermentation (SSF), or as two separate steps, known as SHF (separate hydrolysis and fermentation). The advantage of the former process is a reduction in investment costs [10] and a release of end-product inhibition in the enzymatic hydrolysis. On the other hand, the SHF process allows the enzymatic hydrolysis to be carried out at a higher temperature than the fermentation, which is typically an advantage because of the higher temperature optimum for the enzymatic hydrolysis in comparison to the fermentation [11].

In this study, we intend to the biotechnological potential of cassava stalk for value addition of bioethanol product. The study is aimed to investigate ethanol production from cassava stalk acid and enzyme hydrolysate using mono-culture and co-culture of yeasts fermentation in SHF and SSF.

\section{Materials and Methods}

\subsection{Substrate Preparation}

Cassava stalks were collected and were washed manually using tap water to remove adhering dirt, dried at $45^{\circ} \mathrm{C}$ in a hot-air oven for 4 days, milled, screened to select the fraction of particles with a size of 45-697 $\mu \mathrm{m}$, homogenized in a single lot and stored until needed.

\subsection{Hydrolysate Preparation}

Hydrolysate was prepared by autoclaving under 15 $\mathrm{lb} / \mathrm{inch}^{2}$, the $1.5 \mathrm{~g}$ dried powder of cassava stalks with $100 \mathrm{~mL}$ of $0.1 \mathrm{M}$ sulfuric acid, in conical flasks. Then, $250 \mathrm{~mL}$ filter-sterilize cellulase (Sumitime C; Shin 
Nihon Chemical Co. Ltd., Japan) solution (cellulase activity: 20 Filter paper units (FPU) (g substrate) ${ }^{-1}$, $\alpha$-amylase $\quad 100$ unit $(\mathrm{g} \quad \text { substrate })^{-1}$, amyloglucosidase 100 unit $(\mathrm{g} \text { substrate })^{-1}$, xylanase activity: 500 unit $\left((\mathrm{g} \text { substrate })^{-1}\right)$ and pectinase activity: 250 unit $\left(\left(\mathrm{g}_{\text {substrate }}\right)^{-1}\right)$ in $0.1 \mathrm{M}$ sodium phosphate (pH 5.0) was added to the flask and reacted at $50{ }^{\circ} \mathrm{C}$ and $120 \mathrm{rpm}$ for 48 hours for hydrolysis. After the enzymatic reaction, the hydrolysate was centrifuged at $21,000 \times \mathrm{g}$ for $10 \mathrm{~min}$. The supernatant was supplemented with additional nutrients to give a base medium composition of: $1 \mathrm{~g} / \mathrm{L}$ yeast extract; $2 \mathrm{~g} / \mathrm{L}$ $\left(\mathrm{NH}_{4}\right)_{2} \mathrm{SO}_{4} ; 1 \mathrm{~g} / \mathrm{L} \mathrm{MgSO}{ }_{4} \cdot 7 \mathrm{H}_{2} \mathrm{O}$.

\subsection{Cassava Stalk Hydrolysate Medium}

Fermentation medium composed of $(\mathrm{g} / \mathrm{L})$ : yeast extract 1; $\left(\mathrm{NH}_{4}\right)_{2} \mathrm{SO}_{4} 2 ; \mathrm{MgSO}_{4} \cdot 7 \mathrm{H}_{2} \mathrm{O} 1$.

\subsection{Batch Fermentation}

Batch fermentation was conducted in a $250 \mathrm{~mL}$ conical flask with a working volume of $100 \mathrm{~mL}$. The fermentation medium was inoculated with $5 \% \mathrm{v} / \mathrm{v}$ inoculum (20 hours culture, $1 \times 10^{7}$ cells $/ \mathrm{mL}$ ). The fermentation temperature was kept constant at $30 \pm$ $0.2{ }^{\circ} \mathrm{C}$ in an incubation shaker. The broth was kept under agitation at $50 \mathrm{rpm}$. Samples were taken at regular time intervals during fermentations to determine the concentrations of cell mass, ethanol and residual sugars in the broth. All experiments were carried out in duplicate.

\subsection{Analytical Methods}

Total solids (TSs) moisture and crude protein in cassava stalk were determined according to standards [12]. Cellulose, hemicellulose and lignin contents were determined by the detergent extraction method [13].

\subsection{Biomass Estimation}

Culture dry weight was measured by centrifugation and drying at $105^{\circ} \mathrm{C}$, until no weight change between consecutive measurements was observed.

\subsection{Sugar Estimation}

Total reducing sugar was estimated by using dinitrosalicylic acid (DNS) reagent [14].

\subsection{Ethanol Determination}

The fermentation was carried out at $30^{\circ} \mathrm{C}$ for $18 \mathrm{~h}$. The fermentation broths were filtered through a $0.45 \mathrm{~m}$ Millipore filter. Ethanol in the samples was determined by gas chromatograph using a 60:80 Carbopack B: 5\% Carbowax $20 \mathrm{M}$ glass column. The injector was operated at $200^{\circ} \mathrm{C}$. The flame ionization detector (FID) was kept at $200{ }^{\circ} \mathrm{C}$. Nitrogen gas was used as carrier gas at a flow rate of $30 \mathrm{~mL} / \mathrm{min}$. The temperature was programmed at $120{ }^{\circ} \mathrm{C}$ for $1.4 \mathrm{~min}$, from $120{ }^{\circ} \mathrm{C}$ to $240{ }^{\circ} \mathrm{C}$ at $30{ }^{\circ} \mathrm{C} / \mathrm{min}$, then held $5 \mathrm{~min}$ at $240{ }^{\circ} \mathrm{C}$.

\section{Results and Discussion}

\subsection{Composition of Cassava Stalk}

Production of ethanol through fermentation process from biomass is dependent on its quality. The average composition of cassava stalk is summarized in Table 1. Primarily, the major constituents of cassava stalks are relatively high carbohydrates (cellulose, hemicellulose and starch). The result indicated that cassava stalks could be a good source for bioconversion.

\subsection{Cassava Stalk Acid and Enzyme Hydrolysate Preparation}

Dilute sulfuric acid hydrolysis $(0.1 \quad \mathrm{M})$ under autoclaving under pressure of $15 \mathrm{lb} / \mathrm{inch}^{2}$ at $135{ }^{\circ} \mathrm{C}$ for $10 \mathrm{~min}$ and enzyme hydrolysis as described in materials and methods was very effective in releasing a good amount of sugar from cassava stalks (Table 2). Higher temperature, higher yield of glucose and reducing sugars were released. Approximately 14\% and $21 \%$ of glucose and reducing sugars were released at $120{ }^{\circ} \mathrm{C}$ less than that of at $135^{\circ} \mathrm{C}$, respectively. So, temperature at $135{ }^{\circ} \mathrm{C}$ was suitable to hydrolyse the cassava stalks for sugar production. Approximately $52.73 \%$ and $38.07 \%$ of the reducing sugars and glucose, 
Table 1 Average composition of cassava stalk.

\begin{tabular}{ll}
\hline Constituents & \% of wet weight \\
\hline TSs & $56.24-59.47$ \\
Moisture & $25.47-28.69$ \\
Organic components (\% TSs) & \\
Hemicellulose & $11.62 \pm 0.24$ \\
Cellulose & $21.43 \pm 0.17$ \\
Lignin & $22.64 \pm 0.37$ \\
Crude protein & $2.72 \pm 0.29$ \\
Starch & $8.41 \pm 0.32$ \\
\hline
\end{tabular}

Table 2 Effect of temperature on average sugar composition of cassava stalk acid and enzyme hydrolysate.

\begin{tabular}{lccccr}
\hline Temperature $\left({ }^{\circ} \mathrm{C}\right)$ & \multicolumn{2}{c}{ Glucose $(\mathrm{g} / \mathrm{L})$} & \multicolumn{3}{c}{ Reducing sugars $(\mathrm{g} / \mathrm{L})$} \\
\hline 120 & $5.02 \pm$ & 0.16 & 6.78 & \pm & 0.11 \\
125 & $5.29 \pm$ & 0.12 & 7.04 & \pm & 0.14 \\
135 & $5.71 \pm$ & 0.07 & 7.91 & \pm & 0.05 \\
\hline
\end{tabular}

respectively, were released in the first $10 \mathrm{~min}$ of autoclaving and enzyme hydrolysis, at $30 \mathrm{~min}$ of autoclaving and enzyme hydrolysis, $74.12 \%$ and $54.27 \%$ of the reducing sugars and glucose, respectively, were released after which increase was observed (Table 3). After $60 \mathrm{~min}$ of autoclaving, sugar yield were $84.47 \%$ and $62.40 \%$ of the reducing sugars and glucose, respectively. These sugars were derived primarily from starch and cellulose component. The sugars yield $(84.47 \%)$ was rather high, showing that starch and cellulose almost practically hydrolyzed.

\subsection{Ethanol Production in SHF}

The highest values of ethanol yield per unit biomass $\left(\mathrm{C}_{\mathrm{E}}\right)$, the maximum ethanol production $\left(\mathrm{P}_{\max }\right)$, ethanol production rate $\left(\mathrm{Q}_{\mathrm{E}}\right)$ and product (ethanol) yield coefficient $\left(\mathrm{Y}_{\mathrm{p} / \mathrm{s}}\right)$ were found to be $0.415 \mathrm{~g}$ (g-biomass) $^{-1}, 6.23 \mathrm{~g} / \mathrm{L}, 0.593 \mathrm{~g} / \mathrm{L} /$ hour and $0.502 \mathrm{~g}$ (g-total sugar) $^{-1}$, respectively, by the fermentation of $S$. cerevisiae KM1195. The lowest values of ethanol yield per unit biomass $\left(\mathrm{C}_{\mathrm{E}}\right)$, the maximum ethanol production $\left(\mathrm{P}_{\max }\right)$, ethanol production rate $\left(\mathrm{Q}_{\mathrm{E}}\right)$ and product (ethanol) yield coefficient $\left(\mathrm{Y}_{\mathrm{p} / \mathrm{s}}\right)$ were found to be $0.393 \mathrm{~g}$ (g-biomass $)^{-1}, 5.90 \mathrm{~g} / \mathrm{L}, 0.316 \mathrm{~g} / \mathrm{L} /$ hour and $0.477 \mathrm{~g}$ (g-total sugar) $^{-1}$, respectively, by the fermentation of mono-culture of S. cerevisiae KM7253. It was found that mono-culture of $S$. cerevisiae KM1195 could produce relatively higher ethanol yield than the co-culture (Table 4).
Table 3 Effect of pretreatment time on average sugar composition of cassava stalk acid and enzyme hydrolysate.

\begin{tabular}{llc}
\hline Time $(\mathrm{min})$ & Glucose $(\mathrm{g} / \mathrm{L})$ & Reducing sugars $(\mathrm{g} / \mathrm{L})$ \\
\hline 10 & $5.71 \pm 0.12$ & $7.91 \pm 0.14$ \\
30 & $8.14 \pm 0.17$ & $11.12 \pm 0.09$ \\
60 & $9.36 \pm 0.07$ & $12.67 \pm 0.16$ \\
90 & $9.62 \pm 0.16$ & $12.84 \pm 0.11$ \\
\hline
\end{tabular}

Table 4 Ethanol production by SHF with mono-culture and co-culture.

\begin{tabular}{lllll}
\hline Strain & $\mathrm{C}_{\mathrm{E}}$ & $\mathrm{P}_{\max }$ & $\mathrm{Q}_{\mathrm{E}}$ & $\mathrm{Y}_{\mathrm{p} / \mathrm{s}}$ \\
\hline SHF with single-culture & & & & \\
\hline S. cerevisiae TISTR5048 & 0.398 & 5.97 & 0.612 & 0.479 \\
S. cerevisiae KM1195 & 0.415 & 6.23 & 0.593 & 0.502 \\
S. cerevisiae KM7253 & 0.393 & 5.90 & 0.316 & 0.477 \\
SHF with co-culture inoculation of & & & \\
S. cerevisiae TISTR5048 & 0.405 & 6.07 & 0.781 & 0.489 \\
with C. tropicalis TISTR5045 & & & \\
\hline $\mathrm{C}_{\mathrm{E}}:$ Ethanol yield per unit biomass (g (g-biomass) $\left.)^{-1}\right)$, & \\
$\mathrm{Q}_{\mathrm{E}}:$ Ethanol production rate (g/L/hour), \\
$\mathrm{P}_{\text {max }}:$ Maximum ethanol production $(\mathrm{g} / \mathrm{L})$, \\
$\left.\mathrm{Y}_{\mathrm{p} / \mathrm{s}: \text { Product (ethanol) yield coefficient (g (g-total sugar) }}{ }^{-1}\right)$.
\end{tabular}

\subsection{Ethanol Production in SSF}

The highest values of ethanol yield per unit biomass $\left(\mathrm{C}_{\mathrm{E}}\right)$, the maximum ethanol production $\left(\mathrm{P}_{\max }\right)$, ethanol production rate $\left(\mathrm{Q}_{\mathrm{E}}\right)$ and product (ethanol) yield coefficient $\left(\mathrm{Y}_{\mathrm{p} / \mathrm{s}}\right)$ were found to be $0.414 \mathrm{~g}$ (g-biomass) ${ }^{-1}$, $6.22 \mathrm{~g} / \mathrm{L}, 0.969 \mathrm{~g} / \mathrm{L} /$ hour and $0.486 \mathrm{~g}$ (g-total sugar) $^{-1}$, respectively, by the fermentation of $S$. cerevisiae KM1195. The lowest values of ethanol yield per unit biomass $\left(\mathrm{C}_{\mathrm{E}}\right)$, the maximum ethanol production $\left(\mathrm{P}_{\max }\right)$, ethanol production rate $\left(\mathrm{Q}_{\mathrm{E}}\right)$ and product (ethanol) yield coefficient $\left(\mathrm{Y}_{\mathrm{p} / \mathrm{s}}\right)$ were found to be $0.360 \mathrm{~g}$ (g-biomass $)^{-1}$, $5.42 \mathrm{~g} / \mathrm{L}, 0.911 \mathrm{~g} / \mathrm{L} /$ hour and $0.422 \mathrm{~g}$ (g-total sugar) ${ }^{-1}$, respectively, by the fermentation of mono-culture of $S$. cerevisiae TISTR5048. It was found that mono-culture of S. cerevisiae KM1195 could produce relatively higher ethanol yield than the co-culture (Table 5).

The enzymatic response was evaluated as a function of the temperature and time of pretreatment. The experiments were carried out in order to find the optimal conditions. The temperature ranged from $120^{\circ} \mathrm{C}$ to $135^{\circ} \mathrm{C}$, and the acid concentration was $0.1 \mathrm{M}$ in the optimal test. 
Table 5 Ethanol production by SSF with mono-culture and co-culture.

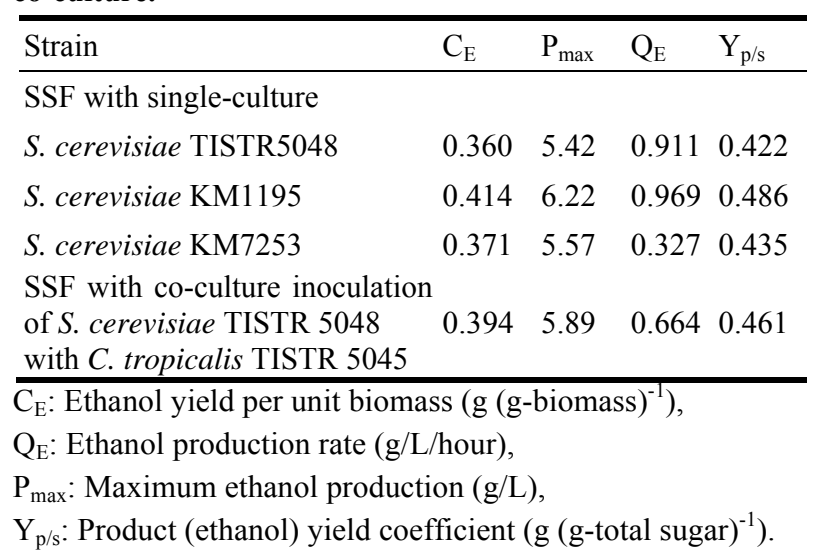

Fig. 1 and Fig. 2 show the time-course for growth, sugar utilization and ethanol concentration in the hydrolysate medium at initial $\mathrm{pH} 5.0 \pm 0.2$ of mono-culture and co-culture of $S$. cerevisiae and $C$. tropicalis. The fermentation parameters are summarized in Tables 4 and 5. Carbohydrate contents of cassava stalks (Table 1) are directly proportional to the yield of ethanol. The yield $\left(\mathrm{C}_{\mathrm{E}}\right)$ and productivities $\left(\mathrm{P}_{\max }, \mathrm{Q}_{\mathrm{E}}\right.$ and $\left.\mathrm{Y}_{\mathrm{p} / \mathrm{s}}\right)$ in SHF and in SSF of mono-culture of $S$. cerevisiae KM1195 relatively high ethanol yield almost equal to the co-culture of $S$. cerevisiae and $C$. tropicalis when grown in the hydrolysate medium. This showed that co-culture of $S$. cerevisiae and $C$. tropicalis fermentation employed for the treatment of the cassava stalk acid enzyme hydrolysate has partially used reducing sugars as substrate but not affected to improve the fermentability. The ethanol production rate $(\mathrm{g} / \mathrm{L} /$ hour $)$ of co-culture comparing to mono-culture of S. cerevisiae KM1195 was higher about $24 \%$ in SHF while ethanol production rate $(\mathrm{g} / \mathrm{L} /$ hour) of co-culture reduced about $32 \%$ in SSF.

However, the ethanol yield of co-culture for the cassava stalk acid enzyme hydrolysate was rather similar to that obtained with S. cerevisiae KM1195

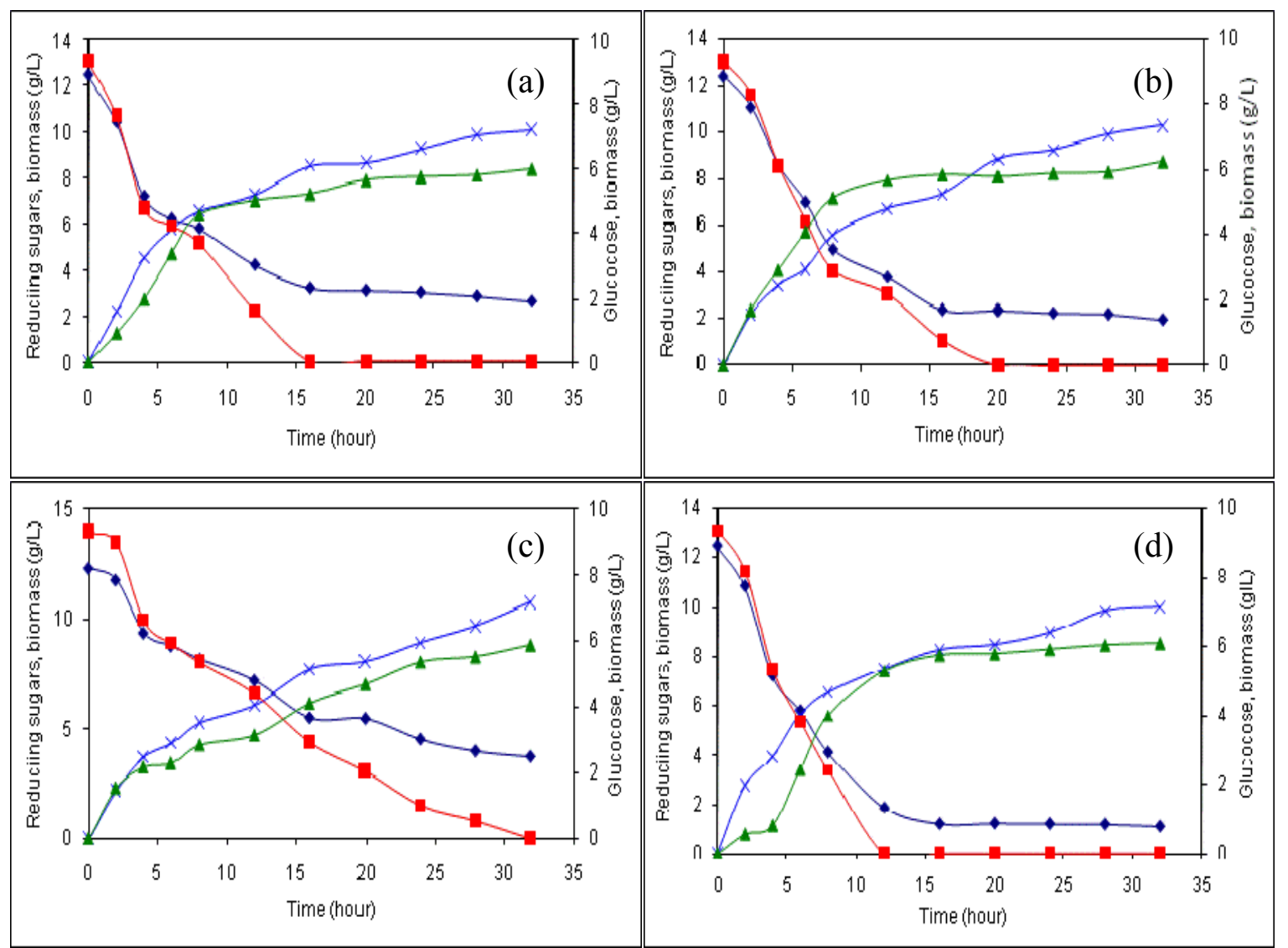

Fig. 1 The time course of growth $(\times)$, reducing sugars $(\diamond)$, glucose $(\square)$ and ethanol $(\Delta)$ concentration in SHF by $S$. cerevisiae TISTR5048 (a), S. cerevisiae KM1195 (b), S. cerevisiae KM7253 (c) and co-culture of $S$. cerevisiae TISTR5048 and C. tropicalis TISTR5045 (d) at $30 \pm 0.2{ }^{\circ} \mathrm{C}$ and $\mathrm{pH} 5.0 \pm 0.2$ using simulated synthetic hydrolysate medium. 


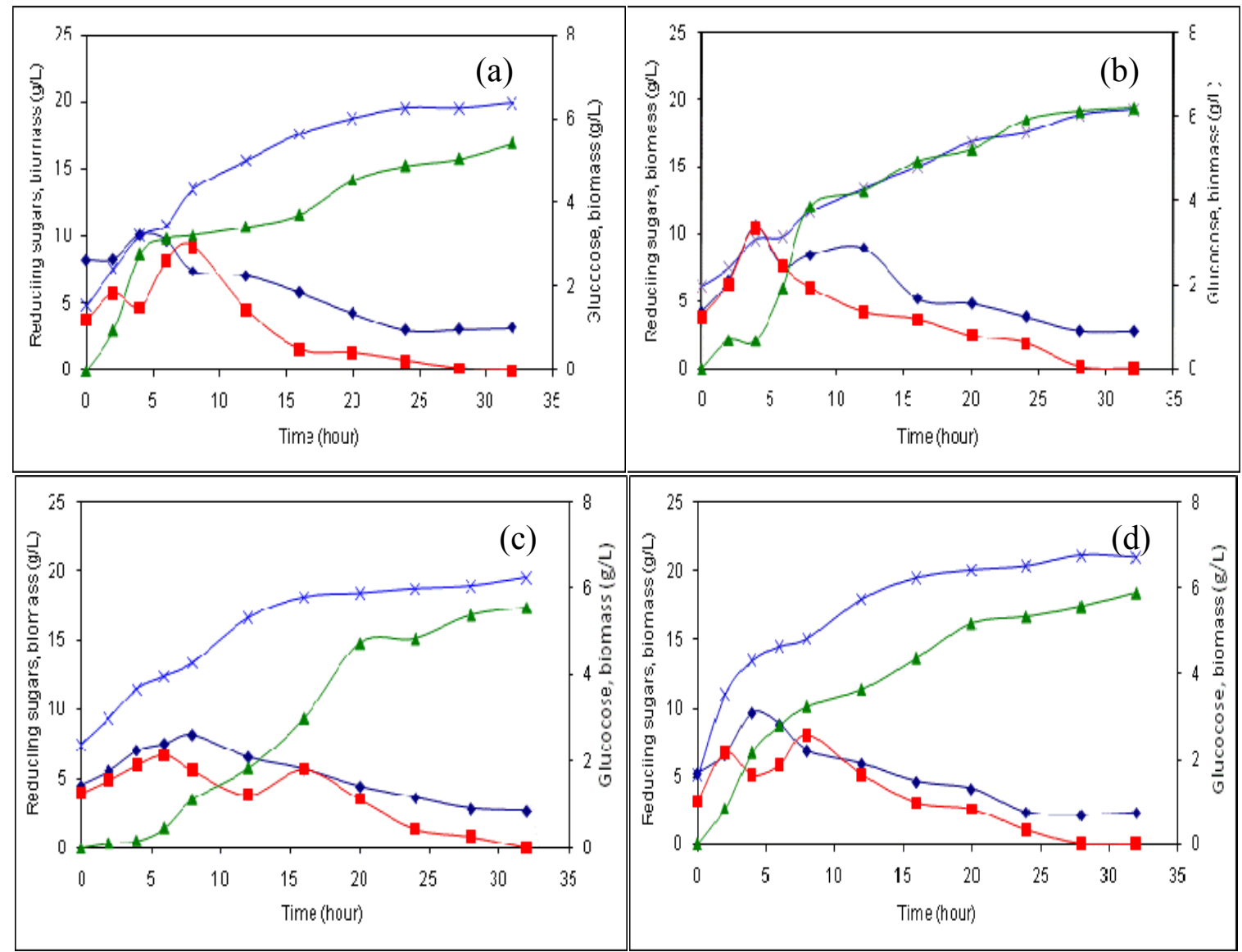

Fig. 2 The time course of growth $(\times)$, reducing sugars $(\star)$, glucose $(\square)$ and ethanol $(\Delta)$ concentration in SSF by $S$. cerevisiae TISTR5048 (a), S. cerevisiae KM1195 (b), S. cerevisiae KM7253 (c) and co-culture of $S$. cerevisiae TISTR5048 and $C$. tropicalis TISTR5045 (d) at $30 \pm 0.2{ }^{\circ} \mathrm{C}$ and $\mathrm{pH} 5.0 \pm 0.2$ using simulated synthetic hydrolysate medium.

(Tables 4 and 5). This shows that there might be some leftover reducing sugars in the treated cassava stalk acid enzyme hydrolysate that are not used in the fermentation performance of S. cerevisiae KM1195.

For producing high quality ethanol, pretreatment of biomass is essential and this leads to better enzymatic hydrolysis fractionate, solubilize, hydrolysis components [15]. Several treatment technologies include concentrated acid [16], dilute acid, alkaline, steam explosion, wet oxidation and liquid hot water. Among these methods, acid hydrolysis is frequently used as a pretreatment because it can be tailored to a wide variety of feedstocks. This method not only exposes starch, cellulose for enzymatic saccharification but also solubilizes hemicellulose and converts it into a fermentable sugar, xylose [17]. However, rapid and efficient fermentation of fermentable sugars is limited because of toxic compounds such as furfural and HMF which are generated during high temperature pretreatment [18] and ultimately inhibits microbial growth. The rationale of dilute sulfuric acid pretreatment of cassava stalk in this study is to obtain a higher yield of monomeric fermentable sugars with an aim to minimize inhibitor generation.

The results showed that SSF with S. cerevisiae KM1195 performed similar to SHF. The temperature optima for the yeast and the enzymes used differ, which means that the conditions used in SSF cannot be optimal for both the enzymes and the yeast. However, advantage of SSF is that when combining the two process (saccharification and fermentation) steps, it results in a lower capital cost and reduces the risk of contamination [19]. However mixing the lignin residue 
with yeast makes yeast recirculation very difficult [20].

Compared to the two-stage hydrolysis-fermentation process, SSF has the following advantages: increase of hydrolysis rate by conversion of sugars that inhibit the cellulase activity; lower enzyme requirement; higher product yields; lower requirements for sterile conditions since glucose is removed immediately and ethanol is produced; shorter process time; and less reactor volume because a single reactor is used.

However, ethanol may also exhibit inhibition to the enzyme activity in the SSF process. Wu and Lee [21] found that cellulase lost $9 \%, 36 \%$ and $64 \%$ of its original activity at ethanol concentrations of 9,35 and $60 \mathrm{~g} / \mathrm{L}$, respectively, at $38^{\circ} \mathrm{C}$ during SSF process. The disadvantages which are considered for SSF include: incompatible temperature of hydrolysis and fermentation; ethanol tolerance of microbes; and inhibition of enzymes by ethanol. Bioethanol production has been improved by new technologies, there are still challenges that need further investigations. These challenges include maintaining a performance of the optimal yeasts in commercial scale fermentation operations, developing more efficient pretreatment technologies for lignocellulosic biomass, and integrating the optimal components into economic ethanol production systems.

\section{Conclusion}

It can be concluded that bioconversion of cassava stalk could be economically useful for the production of ethanol. The maximum values of ethanol yield $\left(\mathrm{C}_{\mathrm{E}}\right)$, productivity $\left(\mathrm{P}_{\max }, \mathrm{Q}_{\mathrm{E}}\right.$ and $\left.\mathrm{Y}_{\mathrm{p} / \mathrm{s}}\right)$ and percent sugar utilization were obtained, when co-culture of $S$. cerevisiae TISTR5048 and C. tropicalis TISTR5045 or mono-culture of S. cerevisiae KM1195 was grown in treated cassava stalk acid enzyme hydrolysate medium both in SHF and SSF at temperature $30 \pm 0.2{ }^{\circ} \mathrm{C}$ and $\mathrm{pH} 5.0 \pm 0.2$. However, SSF may hold promise and focus should be made on developing SSF technologies. Development of efficient microbial strains suitable for bioconversion of cassava stalk is still a largely unexplored area. Efforts should be also made for improving cassava stalk hydrolysis conditions; its effective conversion into fermentable sugars is an area which needs further inputs in terms of research and development. Cassava stalk could serve as a good substrate for production of value-added bioethanol product and the fermentation of cassava stalk for ethanol production was carried out in a high yield by optimum treatment and culture of yeast strains.

\section{Acknowledgment}

The authors acknowledge the financial support received from the National Research University (NRU), Thailand.

\section{References}

[1] C.R. Soccol, Biotechnological products from cassava roots by solid state fermentation, J. Sci. Indust. Res. 55 (1996) 358-364.

[2] M.P. Cereda, L.C. Takitane, G. Chuzel, O. Vilpoux, Starch potential in Brazil, in: D. Dufour, G.M. O'Brien, R. Best (Eds.), Cassava Flour and Starch, CIAT, Cali, Columbia, 1996, pp. 19-24.

[3] A. Pandey, Recent process developments in solid state fermentation, Process Biochem. 27 (2) (1992) 109-117.

[4] K.M. Nampoothiri, A. Pandey, Solid state fermentation for L-glutamic acid production using Brevibacterium sp., Biotechnol. Lett. 16 (2) (1996) 199-204.

[5] A. Pandey, C.R. Soccol, Bioconversion of biomass: A case study of ligno-cellulosics bioconversions in solid state fermentation, Brazilian Arch. Biol. Technol. 41 (4) (1998) 379-390.

[6] G. Hu, J.A. Heitmann, O.J. Rojas, Feedstock pretreatment strategies for producing ethanol from wood, bark, and forest residues, BioResources 3 (2008) 270-294.

[7] A.E. Farrell, R.J. Plevin, B.T. Turner, A.D. Jones, M. O'Hare, D.M. Kammen, Ethanol cancontribute to energy and environmental goals, Science 311 (5760) (2006) 506-508.

[8] F. Parisi, Advances in lignocellulosics hydrolysis and in the utilization of the hydrolysates, Adv. Biochem. Eng. Biotechnol. 38 (1989) 53-87.

[9] T. Puthikitakawiwong, R. Boonsu, O. Joompha, Production of biocoal from cassava stalk, in: M.G. Carvalho, N.H. Afgan (Eds.), New and Renewable Energy Technologies for Sustainable Development, Instituto Superior Tecnico, Portugal, Evora, Portugal, June 28-July 1, 2004, pp. 165-170.

[10] A. Wingren, M. Galbe, G. Zacchi, Techno-economic 
evaluation of producing ethanol from softwood: Comparison of SSF and SHF and identification of bottlenecks, Biotechnol Progr. 19 (4) (2003) 1109-1117.

[11] J. SÖderstrÖm, M. Galbe, G. Zacchi, Separate versus simultaneous saccharification and fermentation of two-step steam pretreated softwood for ethanol production, J. Wood Chem. Technol. 25 (3) (2005) 187-202.

[12] Association of Official Analytical Chemists (AOAC), Methods of analysis of the association of official analytical chemists, Association of Official Analytical Chemists, Washington, DC, 1975.

[13] J.B. Robertson, P.J. van Soest, The detergent system of analysis and its application to human foods, in: W.P.T. James, O. Thiander (Eds.), The Analysis of Dietary Fibers in Food, Marcel Dekker, New York, 1981, pp. 123-158.

[14] G.L. Miller, Use of dinitrosalicylic acid reagent for determination of reducing sugars, Anal. Chem. 31 (1959) 426-428, 591.

[15] B.C. Saha, Hemicellulose bioconversion, J. Ind. Microbiol. Biotechnol. 30 (2003) 279-291.
[16] P.C. Badger, Ethanol from cellulose, in: J. Janick, A. Whipkey (Eds.), Trends in New Crops and New Uses, ASHS Press, Alexandria, General Rev., 2002, pp. 17-21.

[17] B.C. Saha, R.J. Bothast, Pretreatment and enzymatic saccharification of corn fiber, Appl. Biochem. Biotechnol. 76 (1999) 65-75.

[18] E. Palmqvist, B. Hahn-Hagerdal, Fermentation of lignocellulosic hydrolysis, I: Inhibition and detoxification, Bioresour. Technol. 74 (2000) 17-24.

[19] C.E. Wyman, D.D. Spindler, K. Grohmann, Simultaneous saccharification and fermentation of several lignocellulosic feed stocks to fuel ethanol, Biomass Bioenergy 3 (1992) 207-301.

[20] K. Ohgren, R. Bura, G. Lesnicki, J. Saddler, G. Zacchi, A comparison between simultaneous saccharification and fermentation and separate hydrolysis and fermentation using steam pretreated corn stover, Process Biochem. 42 (2007) 834-839.

[21] Z. Wu, Y.Y. Lee, Inhibition of the enzymatic hydrolysis of cellulose by ethanol, Biotech. Lett. 19 (1997) 977-979. 